\title{
USULAN DESAIN PENATAAN LANSKAP PADUKUHAN JETHAK II, SIDOKARTO, GODEAN, SLEMAN
}

\author{
Desy Ayu Krisna Murti ${ }^{1}$, Tri Yuniastuti ${ }^{2}$ \\ ${ }^{1}$ Program Studi Arsitektur, Fakultas Teknik, Universitas Widya Mataram Yogyakarta, \\ Email : \\ desyayu@widyamataram.ac.id \\ ${ }^{2}$ Program Studi Arsitektur, Fakultas Teknik, Universitas Widya Mataram Yogyakarta, \\ Email : \\ Triyuni3@gmail.com
}

\begin{abstract}
Padukuhan Jethak is a tourism village that previously had quite interesting tourism potential to be visited, but over time the change of teachers has resulted in a lack of integrated management. In terms of architecture, it is basically less attractive in terms of landscape arrangement or garden and road arrangement. After being proposed, the program that was run at Jethak II village accepted the proposal based on the proposal from the UWM lecturer team. The hope is that the use of one of the fields of architectural science, namely the landscape, can be realized significantly by the Jethak II community with this program. Some of the main objects are the arrangement of open areas and the development of green plants in open areas in Jethak II. The process is by empowering the community, involving the community directly in the program.
\end{abstract}

Keywords: tourist village, Jethak II, landscape design

\begin{abstract}
Abstrak
Padukuhan Jethak merupakan desa wisata yang dahulunya mempunyai potensi wisata yang cukup menarik untuk dikunjungi, akan tetapi seiring berjalannya waktu pergantian penguru sehingga kurang adanya pengelolaan yang terintegrasi. Dari segi arsitektur pun pada dasarnya kurang menarik dalam segi penataan lanskap atau penataan taman dan jalan. Setelah diusulkan program yang dijalankan padukuhan Jethak II menerima usulan yang diajukan berdasarkan usulan tim dosen UWM. Harapannya adalah pemanfaatan salah satu bidang ilmu arsitektur yaitu lanskap dapat diwujudkan secara nyata kepada masyarakat Jethak II dengan adanya program tersebut. Beberapa hal yang menjadi objek utama adalah penataan area terbuka dan pengembangan tanaman hijau di area terbuka di Jethak II. Adapun prosesnya dengan memberdayakan masyarakat, mengikut sertakan masyarakat secara langsung dalam program tersebut.
\end{abstract}

Kata Kunci: desa wisata, jethak II, desain lanskap

\section{PENDAHULUAN}

Padukuhan Jethak II merupakan padukuhan yang ada di desa Sidokarto kecamatan Godean kabupaten Sleman. Jethak II merupakan desa wisata yang bernama Sidoakur, yang berbatasan dengan padukuhan Klajuran. Namun saat ini padukuhan Jethak II mengalami vakum, hanya beberapa kegiatan saja yang masih dilaksanakan. Sehingga hal ini menginisiasi warga untuk melakukan pembenahan dalam segi fisik agar padukuhan di wilayah Sleman tertata dengan rapi. 
Jethak II berusaha berpartisipasi aktif dalam pelaksanaan program-program pemerintah kabupaten Sleman. Hal ini kemudian menjadi dasar untuk menggerakan warga untuk membenahi secara mandiri akan tetapi masih belum bisa menggunakan sumber daya manusianya secara maksimal. Oleh sebab itu hal ini menjadi kesempatan untuk program studi Arsitektur untuk turut serta membagikan ilmu dalam pembenahan dan penataan dalam ranah padukuhan yang ada di Sleman khususnya Jethak II.

Program Studi Arsitektur, Fakultas Teknik, Universitas Widya Mataram Yogyakarta memiliki visi dan misi melaksanakan pengabdian kepada masyarakat dengan melakukan pendampingan agar mendapatkan manfaat Arsitektur dalam upaya untuk secara terus menerus meningkatkan kesejahteraannyaahapan dan proses desain dan penyuluhan atau penyampaian materi akan dilakukan bersama secara terintegrasi. Hal tersebut yang melandasi untuk turut serta memngembangkan visi dalam upaya memajukan dan membantu memberdayakan masyarakat Jethak II.

\section{Permasalahan Umum}

Banyaknya area yang masih asri di Jethak II menjadikan padukuhan ini cukup potensial untuk dikembangkan lebih lanjut. Kesadaran masyarakat perlu dibangun kembali untuk menggiatkan desa wisata Sidoakur yang sudah terbentuk sejak dulu. Maka pembangunan fisik yang lebih nyata dibutuhkan untuk menunjang hal tersebut. Program studi arsitektur akan mengarahkan bagaimana rencana pengembangan fisik akan dilakukan diantaranya adalah pengembangan lanskap

\section{TINJAUAN PUSTAKA}

a. Konsep Taman Vertikal (Vertical Garden)

Konsep taman vertikal dikenalkan oleh Amerika, Eropa karena lahannya yang sempit. Mereka menemukan inovasi semacam itu untuk tetap menjaga lingkungan ekosistem di sekitar hunian. Jepang kemudian mengenalkan konsep lanjutan yang lebih komprehensif dengan menggunakan bahan-bahan recycle atau bahan daur ulang.

Vertical garden merupakan taman yang dibangun pada bidang yang berdiri tegak lurus dengan tanah. Hal inilah yang membuat vertical garden sering juga disebut dengan model taman dinding. Vertical garden di Indonesia juga sering disebut dengan taman dinding, green wall, vertical landscape, living wall, dan lain sebagainya. Secara sederhana, vertical garden berbeda dengan model taman horizontal yang kita kenal selama ini karena ditanam secara vertikal atau tegak lurus (arsitag.com)

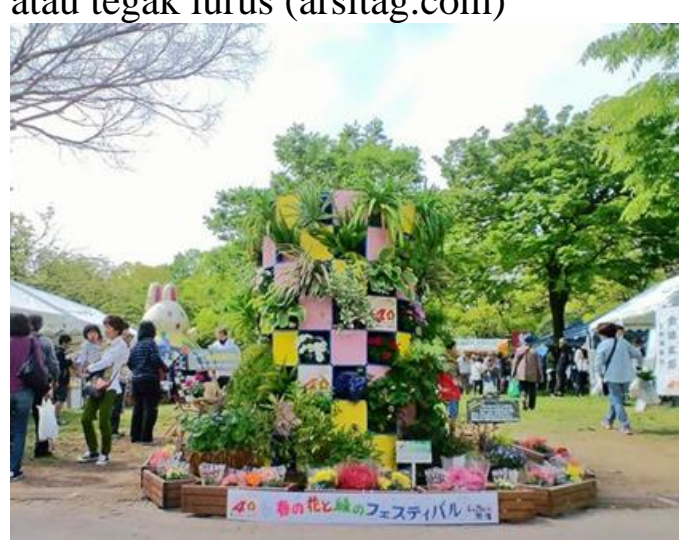

Gambar 2.1 Konsep Taman Vertikal menggunakan bahan recycle di Jepang. Sumber: Pinterest

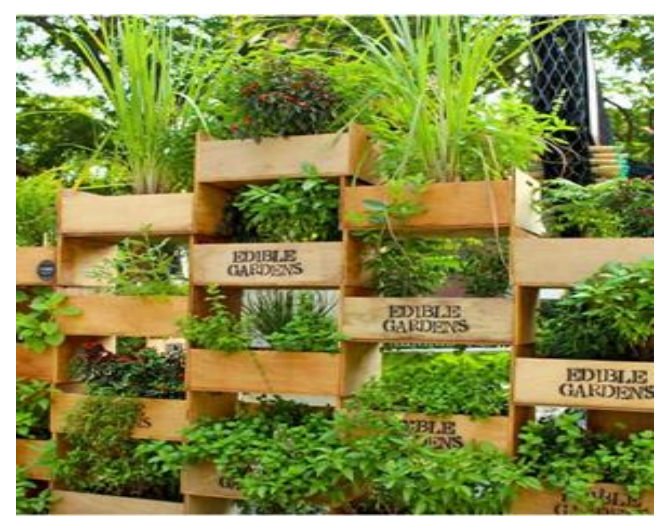

Gambar 2.2 Taman Vertikal di Eropa dengan menggunak an boks kayu bekas. Sumber: Pinterest 
b. Konsep Lanskap

Penataan taman tepian ini mengacu pada konsep pemanfaatan lahan bahu jalan. Namun pada realitanya di sesuaikan dengan kondisi yang ada di Jethak II. Salah satu komponen yang harus ada di dalam taman antara lain: bangku taman, pepohonan, tanaman hias, perdu atau sesuai kebutuhan. Pada sebuah komunitas biasanya akan disesuaikan dengan budidaya yang ada di warga sekitar. Pada beberapa titik akan diusulkan desain seperti contoh sketsa lanskap di bawah ini.

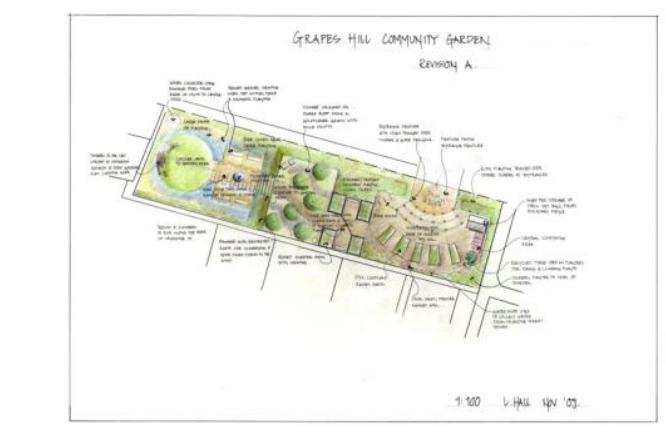

Gambar 2.3 Konsep desain taman di tepi jalan oleh komunitas. Sumber: https://id.pinterest.com.

\section{METODE PENELITIAN}

Metode yang digunakan pada pengabdian kali ini adalah metode kualitatif yang mengedepankan participant observatory. Yaitu dengan keterlibatan dari warga dalam menentukan kebutuhan apa yang paling tepat diterapkan pada kondisi di lapangan. Dalam pelaksanaan kegiatan ini, terdapat beberapa tahapan yang harus dilakukan, yaitu:

a. Survey kondisi lokasi dan koordinasi dengan pihak yang berwenang di Padukuhan Jethak II

b. Menyusun jadwal sesauai kesepakatan tentang penyuluhan bagaimana proses desain.

c. Memberikan informasi terkait jadwal konsultasi tentang penataan lanskap dan bagian mana saja yang menjadi urgensi pelaksanaan. d. Penyuluhan tentang penataan lanskap yang sesuai dengan program studi arsitektur.

e. Pelaksanaan desain kawasan tahap I.

f. Pelaksanaan desain Tahap II.

\section{HASIL DAN PEMBAHASAN}

\subsection{Usulan Desain}

Desa Jethak mempunyai gerbang utama di bagian selatan dekat dengan lapangan Klajuran dan berbtasan dengan sawahsawah. Seperti tergambar pada peta di bawah ini maka gerbang utama ada di dekat kolam milik kas desa Sidokarto yang diperuntukan untuk Padukuhan Jethak II. Karena tidak banyak tanaman yang ada dan dianggap sebagai point of interest maka desain taman vertikal diupayakan di dekat gerbang.

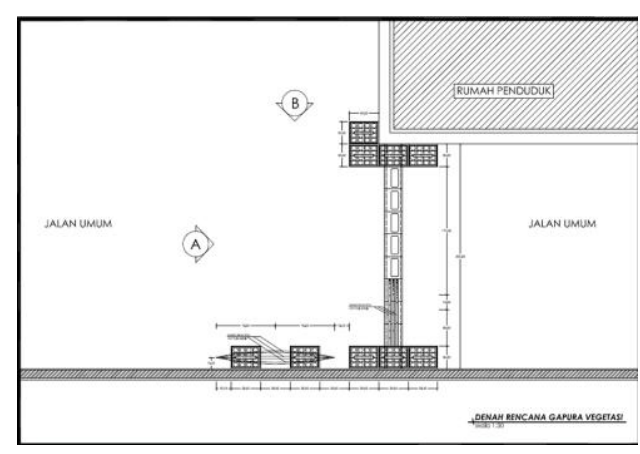

Gambar 4.1 Desain Susunan keranjang tanaman

Pemilihan bahan material antara lain keranjang bekas, yang merupakan bahan yang bisa di dapat dari keranjang minuman atau keranjang gelas. Hal ini bertujuan untuk mengurangi limbah yang terbuang di ada di masyarakat.

Keranjang bekas yang digunakan dari jenis yang sudah disebutkan sebelumnya yaitu dari keranjang bekas botol minuman atau keranjang gelas. Jumlah yang dibutuhkan 16 buah

4.2 Pelaksanaan Kegiatan

1. Penyuluhan 
Kegiatan penyuluhan dilakukan di sela-sela kegiatan warga, yaitu pada acara family gathering

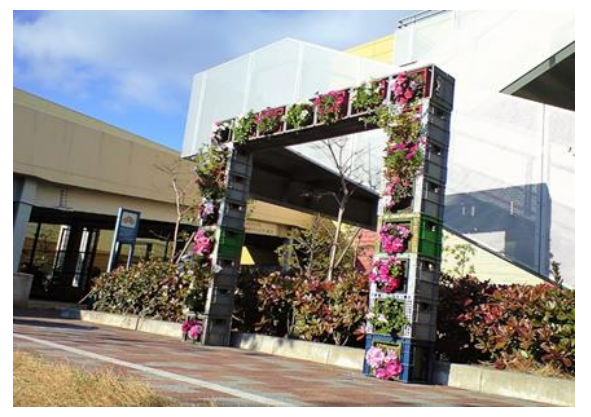

Gambar 4.2 Contoh realisasi Desain Susunan keranjang tanaman. Sumber: https://id.pinterest.com.

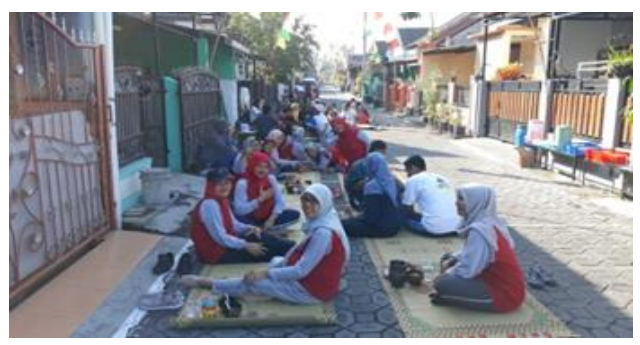

Gambar 4.3. Kegiatan penyuluhan pada acara family gathering Sumber : Dokumentasi, 2019

\section{Kerja Bakti}

Kerja bakti dilakukan oleh warga untuk membersihkan lingkungan dan mengecat pagar dan gapura.

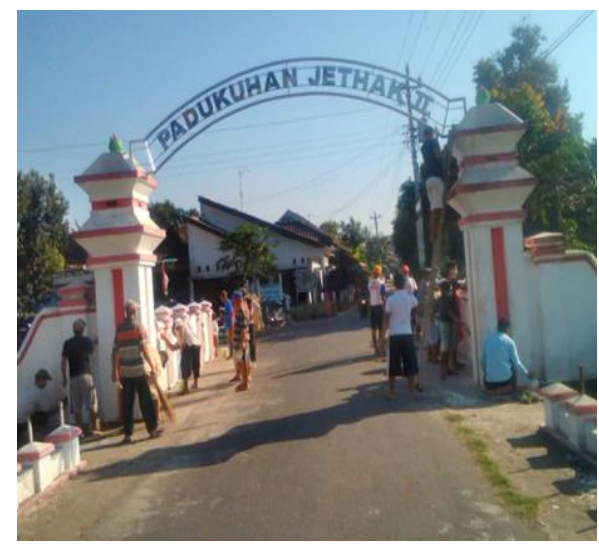

Gambar 4.4. Kerja bakti warga mengecat gapura dan tugu jam.

Sumber : Dokumentasi, 2019

\section{Diskusi dengan Warga}

Diskusi dilakukan bersama dengan Kepala Dukuh dan warga yang akan terlibat dalam pembuatan taman vertikal untuk menentulan waktu dan posisi penempatan taman vertikal menggunakan keranjang bekas. Warga meminta alternatif disain yang diusulkan didisain ulang atau direvisi menyesuaikan kondisi lapangan dan bahan yang akan digunakan.

\subsection{Hasil Kegiatan}

Kegiatan dilakukan sampai tahap diskusi Bersama pak Dukuh dan warga yang akan terlibat. Sedangkan proses pembangunan desainnya akan dilaksanakan pada sabtu dan minggu. Dari gambar di bawah ini sudah ditentukan posisi untuk untuk penempatan taman vertikal menggunakan keranjang. Namun ada beberapa alternative desain yang diminta warga untuk di desain kembali.

Pencarian bahan bekas untuk membuat taman vertikal dilakukan di tempat-tempat pemilahan dan penampungan sampah. Bahan yang sesuai dengan usulan yaitu bekas krat botol minuman sangat susah didapatkan karena langka dan daya gunanya tinggi sehingga kalau dipakakan harus membeli yang baru. Sebagai gantinya adalah beka keranjang buah yang didapatkan dari sampah toko. Dari segi bentuk, ukuran dan kekuatan tidakama dengan bekas keranjang botol minuman, namun masih dapat disusun dan diberi tanaman. 


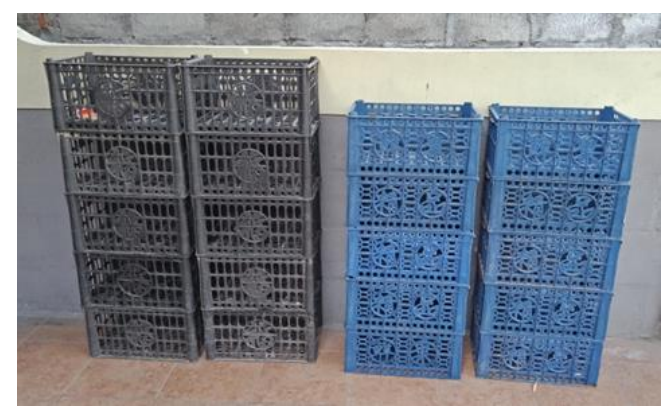

Gambar 4.5 Keranjang buah bekas sebagai media tanam.

Berhubung bahan yang didapatkan untuk membuat taman vertikal tidak sesuai dengan yang direncanakan, maka disainnya mengalami perubahan, menyesuaikan bahan yang ada.

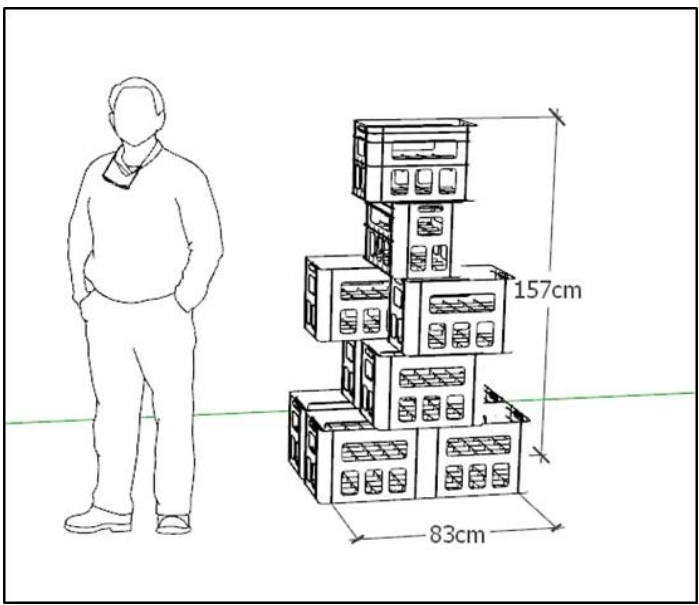

Gambar 4. 6. Revisi Disain taman Vertikal

Sumber : Rancangan Pengabdi, 2019 Pemilihan tanaman menyesuaikan kekuatan keranjang bekas yang akan digunakan. Tanaman yang dipilih adalah tanaman hias dan tanaman obat. Tanaman hias untuk keindahan, misalnya tanaman celosia, pucuk merah, kenikir, brokoli, bayeman warna-warni, dll. Sedangkan tanaman obat untuk diambil manfaatnya untuk pengobatan, misalnya daun mint, parijoto, pegagan, lavender, dll.

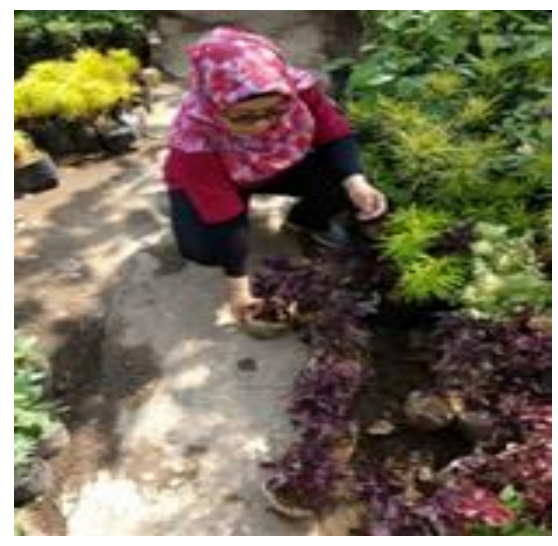

Gambar 4. 7. Pemilihan Tanaman Obat dan Tanaman Hias

Sumber : Dokumentasi, 2019

Tanaman dan keranjang yang dibutuhkan, setelah jumlahnya mencukupi untuk mewujudkan disain taman vertikal, kemudian diserahkan kepada perwakilan warga padukuhan Jethak II untuk diterapkan. Kemudian dilakukan pendampingan cara menyusun kranjang dan menanam tanaman hias dan obat dalam kranjang.
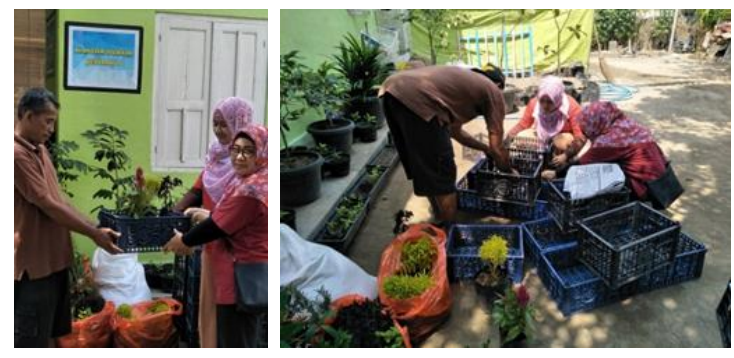

Gambar 4.8. Penyeranhan Bahan dan Pendampingan Penataan Taman Vertikal

Sumber : Dokumentasi, 2019

Dengan adanya contoh taman vertikal di depan gapura yang bisa dilihat oleh semua warga ini diharapkan masyarakat dapat mengambil contoh pemanfaatan barang bekas untuk memperindah lingkungan dan bisa diterapkan pada masing-masing lahan. 


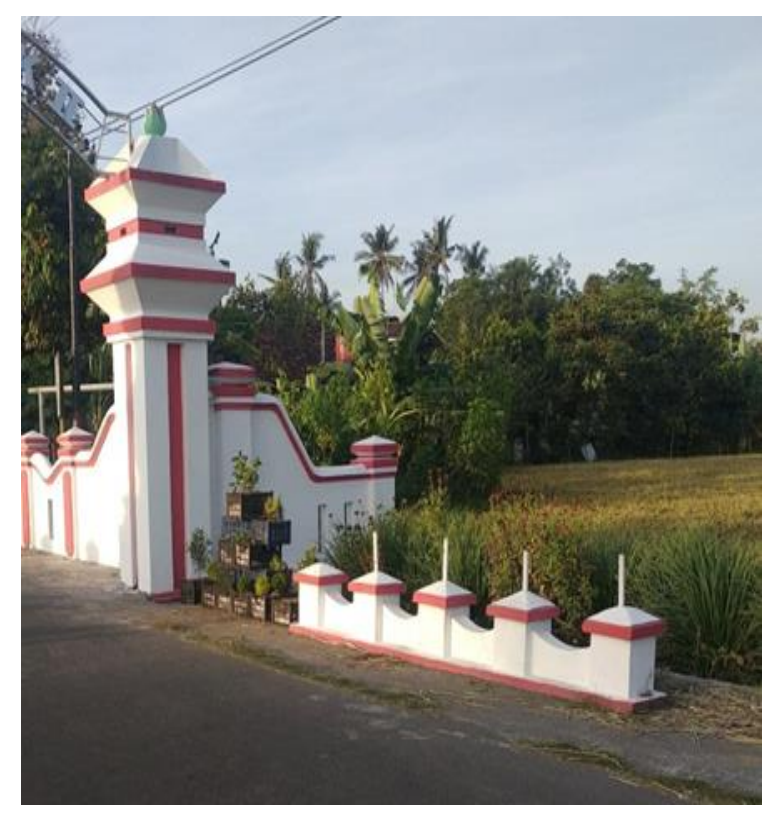

Gambar 4.9. Penataan taman pada gerbang Padukuhan Jethhak II. Sumber : Dokumentasi, 2019

\section{KESIMPULAN}

Warga dan kepala padukuhan menyetujui desain yang disulkan dengan beberapa perubahan desain dan revisi yang dilakukan dengan diskusi bersama. Meskipun banyak agenda yang dilakukan oleh Padukuhan Jethak II, namun kegiatan penataan taman vertikal dapat dilaksanakan meskipun tidak tepat waktu sesuai jadwal kegiatan.

Langkah berikutnya yang penting adalah pemeliharaan dan pemantauan. Pihak warga dihimbau untuk dapat memelihara taman vertikal yang ada didepan gapura dengan secara rutin menyiram tanaman agar tidak mati/layu. Sumber air yang dapat dimanfaatkan adalah air sungai/parit yag ada di tepi gapura. Namun bila musim kering, maka sumber air dapat diambil dari kolam ikan yang tidak jaur dari gapura. Hal ini membutuhkan kesediaan waktu dan tenaga dari warga. Pemantauan juga harus dilakukan oleh tim pengabdi untuk memastikan bahwa taman vertikal dapat terpelihara dengan baik.

\section{DAFTAR PUSTAKA}

BPS Kab. Sleman. Sleman dalam Angka 2018. Badan Pusat Statistik Sleman.

Lestari, Garsinia. Dkk. 2015. Tanaman Hias Lanskap. Penebar Swadaya. Depok.

Muhlisah, Ir. Fauziah. 2016. Tanaman Obat Keluarga. Penebar Swadaya. Depok

White, Edward T. 1983. Site Analysis Diagramming for Architetural Design. Architecture Media. United States.

Slemankab.go.id. Agenda Lomba Toga 